\title{
Factors affecting conditional discrimination learning by pigeons: II. Physical and temporal characteristics of stimuli
}

\author{
DAVID R. THOMAS, PATRICK J. CURRAN, and RICHARD J. RUSSELL \\ University of Colorado, Boulder, Colorado
}

\begin{abstract}
Four experiments were performed to determine the stimulus characteristics that favor the development of conditional stimulus control in the single reversal paradigm with pigeon subjects. In Experiment 1, pigeons were trained on a successive discrimination between tone frequencies ranging from 350 to $3500 \mathrm{~Hz}$ in a particular houselight context condition (houselight-on or -off). The subjects then were trained on the reversal of the tone discrimination in the alternative context. Subsequent tone-frequency generalization testing in the two contexts indicated that they had failed to gain conditional control over the pigeons' discriminative performance. Such control was obtained in Experiment 2, in which the two problems were alternated daily for 32 sessions of training. The gradients then peaked at the appropriate $\mathrm{S}+$ value in each context. In Experiment 3, the key colors (blue vs. red) served as contexts while pigeons learned a successive discrimination in which the discriminative cues were houselight-on versus houselight-off conditions. This was followed by a reversal of the discrimination in the alternative key-color context condition. The key colors were effective conditional cues in this situation. In a previous experiment (Thomas, McKelvie, \& Mah, 1985), key color had been ineffective as a conditional cue when the discriminative cues were lines superimposed on the colored background. In Experiment 4, key color was effective when the color and lines were presented on a single key as in the earlier experiment, but were sequenced such that the onset of the key color preceded and then overlapped the presentation of the lines. We concluded that conditional discriminations are easiest for pigeons when visual cues are used, but the conditional and discriminative cues must be presented in such a way that they do not combine to form a psychological compound.
\end{abstract}

A typical procedure for studying conditional discrimination learning is to use a background stimulus to indicate the significance of the discriminative stimuli. Thus, in a classic experiment, Lashley (1938) trained rats to select an upright rather than an inverted triangle when the stimulus cards had plain backgrounds and to choose the inverted triangle when the backgrounds were striped. Thomas, McKelvie, Ranney, and Moye (1981) developed a variation of this general procedure, called the single reversal paradigm, in which training on one of the two component problems is completed before training on the reversal problem is initiated. In particular, their procedure begins by training pigeons on a successive discrimination, for example, between two key colors, in the presence of a particular environmental context, such as houselight-on (HL). When the discrimination is mastered after several sessions, the pigeons are then trained on the reversal of the discrimination in the alternative context (houselight-off, $\overline{\mathrm{HL}}$ ). Later, retention is assessed via a wavelength generalization test in extinction, with the two contexts alternating in blocks of test trials. The result is that the gradients peak at the appropriate value in each context, indicating that, during training, a conditional rela-

The authors' address is Department of Psychology, Campus Box 345, University of Colorado, Boulder, CO 80309. tionship forms between the environmental contexts and the on-key stimuli (see Thomas, McKelvie, \& Mah, 1985; Thomas et al., 1981). The success of this paradigm in establishing a conditional relationship in very few training sessions is quite striking in contrast to the extreme difficulty with which pigeons have acquired conditional discriminations when both the conditional and discriminative cues have been projected on the response key (see Boneau \& Honig, 1964; Richards, 1979). This difference led Thomas et al. (1985) to propose that pigeons may be predisposed to use global environmental cues as conditional stimuli because they identify the place in which food has been obtained. On the other hand, localized on-key stimuli may most readily serve as discriminative cues, exerting a more direct effect on behavior, in part, because responding is physically directed at them.

Thomas et al. (1985) showed that houselight contextual cues gained conditional control over discriminations based on the angle of a line projected on the response key. With a different group of pigeons, the context used was the color on the key on which the lines were superimposed: blue for the original problem and red for the reversal. Interestingly, the key colors did not gain conditional control, with the gradients showing recency, with peaks at the reversal, $\mathbf{S}+$, regardless of the key-color context present. This finding is particularly striking, because 
pigeons' sensitivity to the color projected on the response key is legendary. Indeed, the bulk of the operant stimulus control literature with pigeons is based upon such stimuli (see Honig \& Urcuioli, 1981). Thomas et al. (1985) suggested that key color might have failed to play a conditional role in their study, in part, because the color with a line superimposed upon it might have formed a psychological compound, or gestalt, which could have hindered the perception of a hierarchical relationship between its constituent elements.

The general purpose of the research program of which this study is a part is to determine the conditions that influence the development of conditional relations between stimuli and to develop an understanding of why they do so. Thus, a study reported by Thomas and Goldberg (1985), contrasted three different training procedures: the single reversal procedure, as described above; a more typical procedure in which all combinations of conditional and discriminative stimuli are experienced within sessions; and an intermediate procedure, called conditional serial discrimination reversal (CSDR) training, in which the original and reversal problems are alternated on a daily basis. With the houselight and key-color stimuli used in the Thomas and Goldberg experiment, the training paradigm made relatively little difference, although the traditional within-session group performed somewhat more poorly than did the other two groups. Presumably, this was due to the interference between conflicting memories; that is, the key-color or houselight condition that signaled reinforcement on Trial $n$ may have signaled nonreinforcement on Trial $n-1$.

The specific purpose of the present study was to investigate the factors that may contribute to the success of the houselight conditions and the failure of the key-color conditions to gain conditional control in the single reversal paradigm. If the houselight is effective because it identifies the place where food-reinforced responding has occurred, it follows that the discriminative cues used should make little difference, as long as the subjects are capable of discriminating between them. Thus, in Experiment 1, we employed the same houselight contextual cues used successfully in our prior experiments, except that the discriminative cues were different frequencies of tone. In the original work with the single reversal procedure by Thomas et al. (1981), the contexts were compounds consisting of visual elements ( $\mathrm{HL}$ or $\overline{\mathrm{HL}}$ ) and auditory ones (pure tone vs. white noise). In subsequent experiments by Thomas et al. (1985), it was shown that the auditory element played no role in the conditional control that was achieved. Furthermore, this outcome was not due to overshadowing the auditory cue with the visual one. In an experiment in which only the auditory cues were used as contexts during single reversal training, no conditional control was developed by those cues.

In view of the work by LoLordo (1979) and others on selective associations in pigeons, it was not surprising that the visual contexts would be more effective than the au- ditory ones in a feeding situation. The total ineffectiveness of the auditory cues as contexts was somewhat surprising, however, in view of the fact that the pigeons had noticed those cues, as evidenced by the disruption of keypecking when the auditory contexts were switched for reversal training. Of course, noticing the cues may be a necessary condition, but not a sufficient one, for forming an association between those cues and other events or relationships. In Experiment 1, the auditory cues were used as explicit discriminative stimuli, thus there could be no question that these cues had entered into a direct associative relationship to behavior. The question that remained was whether they would also take part in an indirect (conditional) relationship to behavior.

\section{EXPERIMENT 1}

\section{Method}

Subjects. The subjects were 12 experimentally naive pigeons obtained from a local supplier and maintained at $80 \%$ of their ad-lib weights. They were housed in individual cages in a colony room with a 16:8-h light:dark cycle. Light onset was at 7:00 a.m., and the subjects were run daily (except on weekends) starting at 3:00 p.m.

Apparatus. The apparatus was the same as that used by Thomas et al. (1981). A tone generator provided tones of 350, 670, 1500, and $3500 \mathrm{~Hz}$ at $80 \mathrm{~dB}$ SPL (re .0002 dynes $/ \mathrm{cm}^{2}$ ). Reinforcement was 3-sec of access to the food hopper filled with mixed grain. Recording and control were accomplished with the use of a Commodore Pet Professional Computer (Model 2001) with a locally designed and constructed interface.

Procedure. In preliminary training, all 12 subjects were treated similarly. They were magazine-trained and shaped by the method of successive approximations to peck a key illuminated by white light. Next, they were placed for several days on a variable interval reinforcement schedule with gradually increasing interreinforcement intervals. On Day 1 of VI 30-sec training, the subjects were divided into two groups to counterbalance the two contexts. For all subjects, on Problem 1, S+ was a low-pitched tone $(350 \mathrm{~Hz})$ and $S-$ was a high-pitched tone $(3500 \mathrm{~Hz})$. For half the subjects, Context 1 was houselight-on (HL), and for half it was houselightoff $(\overline{H L})$. Responding to $S+$ was reinforced on a VI 30-sec schedule, whereas responding to $S-$ was extinguished. Sixty-minute training sessions were run daily. Each session consisted of three blocks of 10 trials, with each block including five presentations of $S+$ and five of $\mathrm{S}$ - in a nonsystematic order. Each trial was $117 \mathrm{sec}$ in duration, with a 3-sec blackout between trials. During blackouts, the houselight and the keylight were turned off. Thus, the houselight, keylight, and tone stimuli were always presented and terminated simultaneously. After 15 sessions of this training, all subjects were shifted to Phase 2 of Experiment 1.

In Phase 2, trials and blackouts were of the same durations as those in Phase 1; however, the discrimination problem was the reversal of that learned in Phase 1 (i.e., $S+$ was now $3500 \mathrm{~Hz}$ and $S$ - was now $350 \mathrm{~Hz}$ ), and the context present for each subgroup was the alternative to that present during Phase 1 . After 15 days of Phase-2 training, on the next day, all subjects received a generalization test in extinction. The four tones with auditory frequencies of $350,670,1500$, and $3500 \mathrm{~Hz}$ were randomized into blocks, and 12 different blocks were presented to each subject. Stimulus presentations were 60 -sec in duration, separated by 5 -sec blackouts. All subjects started the test in their Context-1 condition, and the contexts were alternated after every two blocks of test trials. 


\section{Results and Discussion}

Because there were no differences in training or testing due to the counterbalancing of context conditions, the data were pooled over the two subgroups. All subjects acquired the tone frequency discrimination, and on the 15th session of Problem-1 training, a mean of $78.5 \%$ of total responses was emitted during $\mathrm{S}+$ periods (range 64\%-97\%). Keypecking had to be reshaped for most subjects at the start of reversal training, but there were no subsequent differences in performance between subjects that required reshaping and those that did not. The subjects finished Problem-2 training with a mean of $81.9 \%$ of total responses to $S+$ (range 56\%-99\%) in the last training session.

For each subject, a generalization gradient was computed on the basis of its responses in each context. The two gradients for each subject are presented in Figure 1, along with the median gradients for all 11 subjects. The performance of the subjects during generalization testing was highly variable. Not a single subject showed strong conditional control by the houselight contexts, in the sense that none showed both highest and lowest response rates at the appropriate $\mathbf{S}+$ and $\mathbf{S}-$ values in each context. Only 3 subjects $(002,005$, and 007$)$ showed maximal responding to the appropriate $S+$ in each context, and only $2(001$ and 003) showed minimal responding to the appropriate
$\mathrm{S}-$ in each context. Two subjects (009 and 017) showed a clear recency effect, with maximal responding to the Problem-2 S + regardless of which context was present, and Subject 019 also showed recency by responding maximally to the Problem-2 S+ when tested in Context 1. Indeed, the most critical indicator of conditional control is the subjects' performance in Context 1 , since the tendency of subjects to show recency favors appropriate responding in Context 2 . Only 2 subjects (002 and 003) showed clearly appropriate responding in Context 1 , whereas 2 other subjects ( 005 and 015$)$ responded almost equally to both former $S+$ values.

Because conditional stimulus control is manifested as differences in discriminative stimulus control in the presence of different conditional stimuli, it follows that the degree of discriminative control that has been developed places a ceiling on the degree of conditional control that can be exercised. It is important to note, therefore, that in an experiment reported by Thomas and Curran (1987), using a treadle press response and houselight and key color cues, strong conditional control was achieved despite the fact that discrimination performance during training was comparable to that obtained in our Experiment 1. Furthermore, within Experiment 1, there was no relationship between the level of performance during reinforced training and the level of performance during gener-
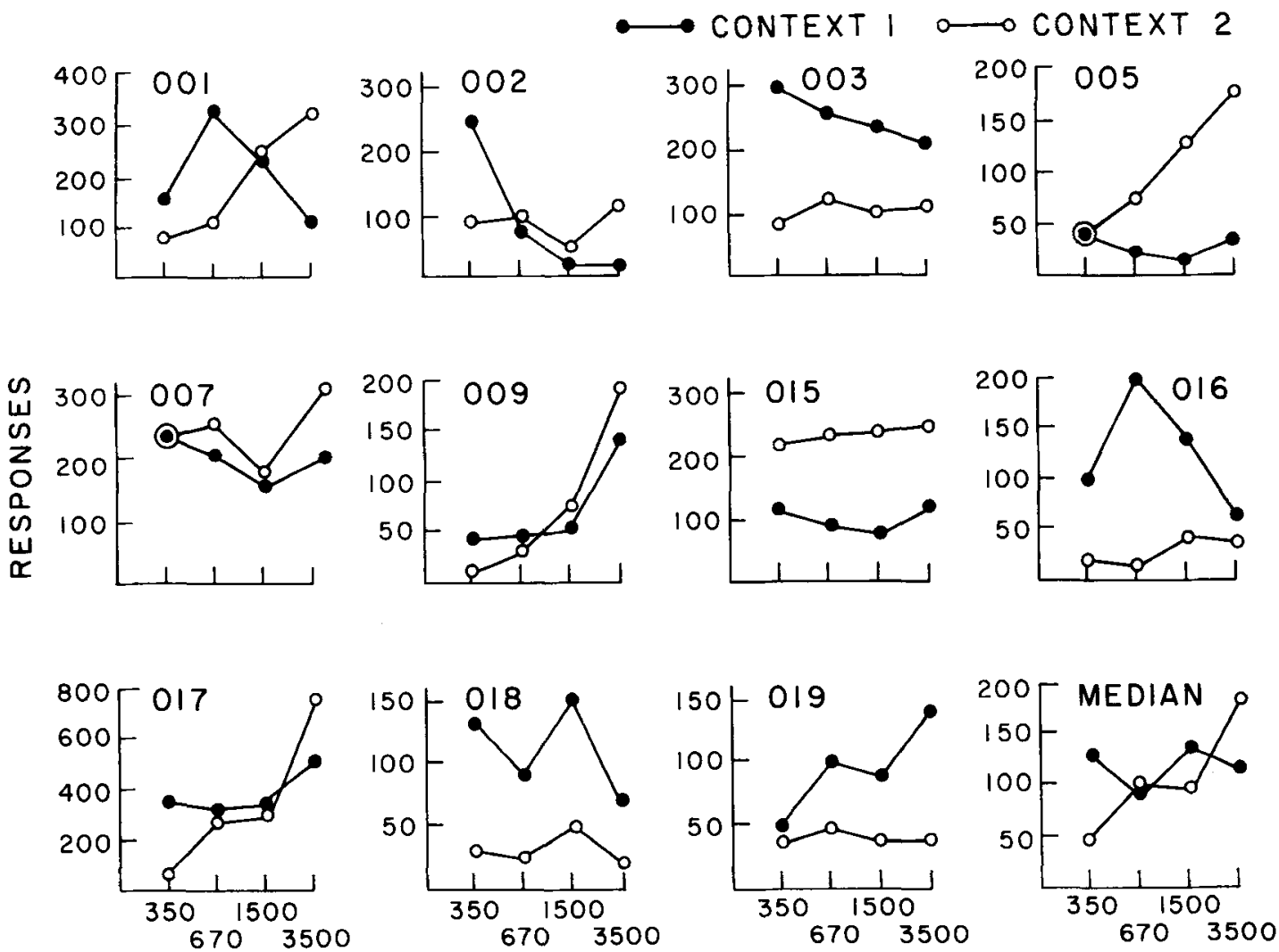

$\mathrm{Hz}$

Figure 1. Individual and group median tone-frequency generalization gradients in two different houselight contexts following single reversal training. 
alization testing in extinction. Thus, for example, Subjects 002,005 , and 007 , which showed the strongest evidence of conditional control during testing, averaged $64 \%, 76 \%$, and $91 \%$ to $S+$ (pooled for the two discrimination problems), whereas Subjects 001,015 , and 017 , which showed no evidence of conditional control, averaged $97 \%, 82 \%$, and $82 \%$. We must conclude that the failure of the houselight cues to consistently gain conditional control must be due to the use of the auditory stimuli as discriminative cues.

With the single reversal paradigm, the learning of a conditional relationship between the context and the discriminative cues is implicit in the sense that it is not observable during training and is revealed only in generalization testing when the two contexts are alternated. Furthermore, there is only one opportunity to compare the two contexts during training, and the original and reversal problems could be mastered without the context playing any role whatsoever. The acquisition of a conditional discrimination may be facilitated by the use of a procedure in which conditional control is explicit in the sense that the use of the conditional cues facilitates the mastery of the task. Thomas, Stengel, Sherman, and Woodford (1987) recently showed that floor tilt and texture cues may gain conditional control over discriminations based upon key color via the use of a CSDR procedure, although extensive training with the single reversal procedure was ineffective with these cues. This result is in contrast to that reported by Thomas and Goldberg (1985), who found no difference between single reversal and CSDR procedures when houselight and key-color cues were used. It seems reasonable to assert that the houselight cues are so salient that repeated alternation is unnecessary to call the pigeons' attention to them. In Experiment 2, we inquired whether CSDR training with the houselight and auditory cues used in Experiment 1 would be successful in establishing a conditional relationship between these cues. It was not obvious whether CSDR training would be effective in Experiment 2, because the problem was clearly not the lack of salience of the conditional cues but rather the failure of those cues to form an association with the auditory discriminative cues.

\section{EXPERIMENT 2}

\section{Method}

Subjects. The subjects used in Experiment 1 were used again.

Apparatus. The apparatus was the same as that used in Experiment 1.

Procedure. On the day after the test for generalization, the subjects were trained on Problem 1 in Context 1 . On the next day, they were trained on Problem 2 in Context 2. The two problems, each in its paired context, were alternated for a total of 32 sessions, followed by a generalization test similar to that administered at the end of training in Experiment 1.

\section{Results and Discussion}

On the last two sessions of CSDR training, the subjects showed means of $78.2 \%$ (range $62 \%-86 \%$ ) and $79.1 \%$ (range 67\%-82\%) of total responses to S + on Problem 1 and Problem 2, respectively. These performance levels are roughly comparable to those that had been produced by single reversal training on the same two problems, although no subjects showed extremely high levels of performance during CSDR training. As Thomas and Goldberg (1985) pointed out, CSDR training may lead to poorer daily performance than single reversal training because of the opportunity for interference by the memory of the previous day's training experience. On the other hand, it may lead to better conditional control (as it did in the Thomas et al., 1987, study with the floor tilt and texture contextual cues), because it provides multiple opportunities to contrast the different contextual cues. This may increase the salience of those cues, and it may also facilitate the formation of an association between the contextual cues and the discriminative stimuli used in their presence.

Figure 2 presents the individual generalization gradients under each context condition for each subject and the group mean gradients obtained under each context. Most of the gradients show strong evidence of conditional control by the houselight contexts, with both maximal and minimal responding to the appropriate $S+$ and $S-$ in each context.

Because the pigeons in Experiment 2 had previously been exposed to single reversal training and to a test of generalization in extinction in Experiment 1, it is important to consider the possibility that those prior experiences, perhaps in combination with CSDR training, may have accounted for the positive result of Experiment 2. A similar question was raised in the study by Thomas et al. (1987), in which, in their Experiment 1, single reversal training with floor tilt and texture contextual cues was ineffective, whereas subsequent CSDR training was effective with the same cues. The possible role of the initial single reversal training was addressed in their Experiment 2 , in which independent groups received 30 sessions of either single reversal or CSDR training. The CSDR group yielded excellent evidence of conditional control by the floor tilt and texture cues, whereas the single reversal group showed only recency. Thus, it seems virtually certain that the positive results of our Experiment 2 were due to the CSDR procedure employed and not to the subjects' prior experimental history. We may conclude that the benefit of CSDR training is not restricted to situations in which the conditional cues are low in salience. The daily alternations between conditions also must facilitate the formation of an association between the already highly salient houselight cues and the auditory discriminative stimuli.

We return now to a consideration of why key color was ineffective as a conditional cue when line-angle discriminative stimuli were used in the experiment by Thomas et al. (1985). If the houselight cues are not invariably effective as contextual (conditional) cues, perhaps key color will not be invariably ineffective. The ineffectiveness of key color in the experiment by Thomas et al. (1985) might have had nothing to do with the fact that 

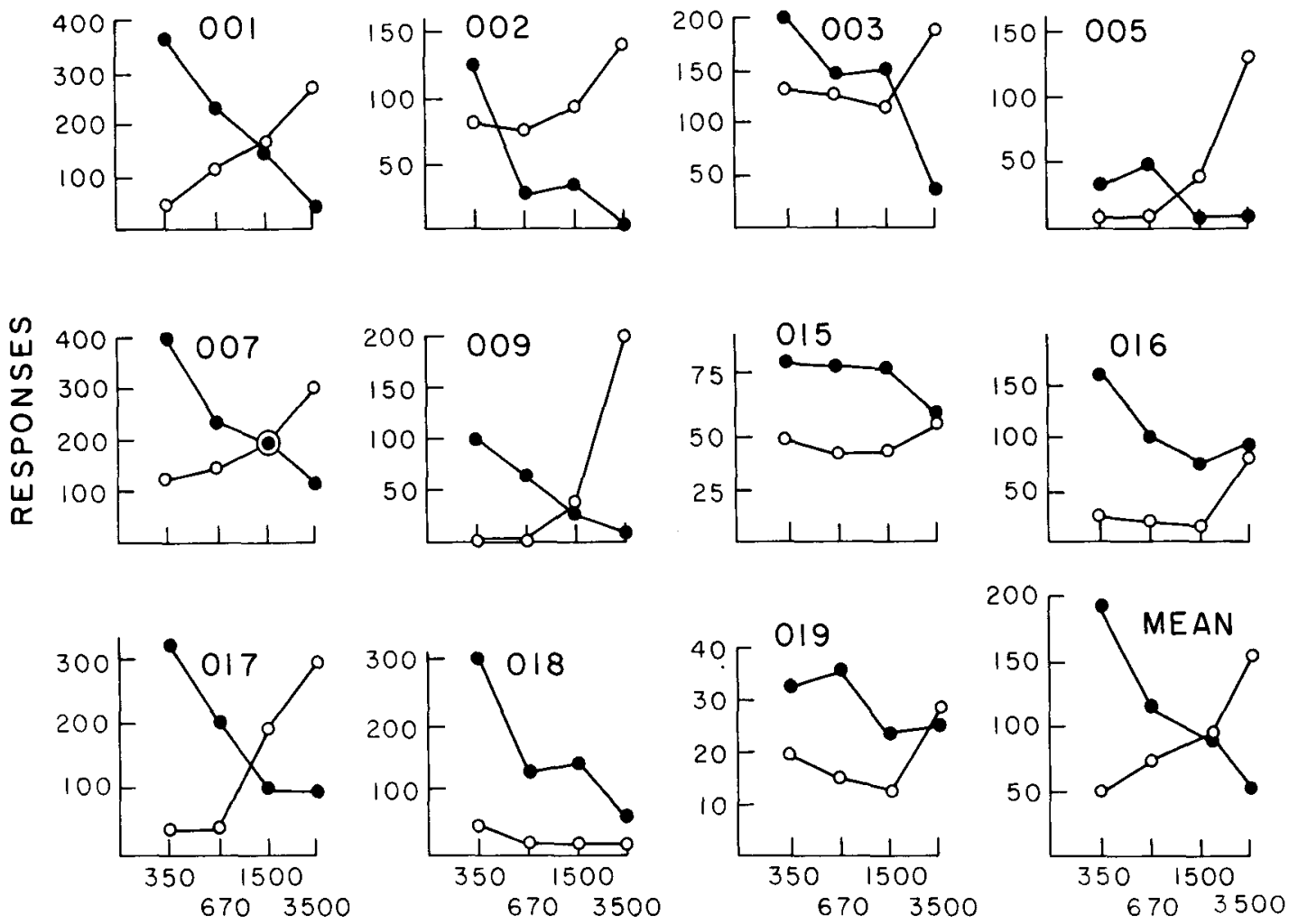

$\mathrm{Hz}$

Figure 2. Individual and group mean tone-frequency generalization gradients in two different houselight contexts following CSDR training.

it was a localized cue toward which responding was directed, but only with the fact that it entered into compound with the line-angle discriminative cues. One way to test this possibility would be to use key color as the context in combination with discriminative cues with which it would not form a compound. This is clearly the case with houselight cues, which have been paired successfully with key colors in several of our past experiments. In those experiments, of course, the houselight was the conditional cue, and the key color was the discriminative one. In Experiment 3, we asked whether these functional roles can be reversed; that is, Will a key-color contextual cue gain conditional control over discriminative performance based upon houselight cues?

\section{EXPERIMENT 3}

\section{Method}

Subjects. The subjects were 8 experimentally naive pigeons, maintained as in Experiment 1.

Apparatus. The same apparatus was used as in Experiment 1. The houselight in the chambers consisted of a GE 1820 bulb behind a 4-cm frosted Plexiglas strip, which was at the top of and covered the full length of the intelligence panel. The intensity of the houselight was rheostatically controlled and could be set at four different values. These values were $5.0,3.7,1.3$, and $0 \mathrm{fc}$, as measured with a Simpson Illumination Level Meter (Model 408) at a point directly in front of the response key. The $\mathrm{HL}$ and $\overline{\mathrm{HL}}$ conditions used in training were the 5.0 - and $0-\mathrm{fc}$ values, respectively. A white-noise generator provided masking noise throughout training and testing. Key stimuli were produced by IEE projectors (Series 0010 ) with No. 1820 lamps operated at $12 \mathrm{~V}$. Kodak Wratten filters Nos. 75, 74, 99, 73, and 72B produced nominal peaktransmitted wavelengths of $490,538,555,576$, and $606 \mathrm{~nm}$, respectively.

Procedure. All subjects were magazine-trained and shaped by the method of successive approximations to peck the key, that was illuminated by a light of $490 \mathrm{~nm}$ (blue). Next, they were placed for several days on a variable-interval reinforcement schedule with gradually increasing interreinforcement intervals until a VI 30 -sec schedule was in effect. Throughout the preliminary training, the houselight was on in the operant chambers. On the next day, discrimination training was initiated. For all subjects, the HL was $\mathrm{S}+$, and the $\overline{\mathrm{HL}}$ was $\mathrm{S}-$. Responding to $\mathrm{S}+$ was reinforced on a VI $30-$ sec schedule whereas responding to $S-$ was extinguished. Thirtyminute training sessions were run daily, consisting of three blocks of 10 trials with each block including five presentations of $\mathrm{S}+$ and five of $\mathrm{S}-$ in a nonsystematic order. Each trial was $55 \mathrm{sec}$ in duration, separated by 5 -sec blackouts, during which both the houselight and the keylight were turned off. The blue keylight illuminated the key during all trials. After six sessions of Phase-1 discrimination training, Phase 2 of training was initiated. In Phase 2, the problem was the reversal of that learned in Phase 1 (i.e., $\overline{\mathrm{HL}}$ was now $S+$ and HL was $S-$. The red (606 nm) keylight was present during all trials in Phase 2, which also lasted for six sessions.

On the day after the completion of Phase 2 of training, all subjects were tested for generalization in extinction. Four different 
houselight intensities, 5.0, 3.7, 1.3 and $0 \mathrm{fc}$, were randomized into blocks, and eight different blocks were presented to each subject. As during training, trials lasted $55 \mathrm{sec}$, and were separated by 5 -sec blackouts. The subjects were divided into two groups of four for purposes of testing. Half of the pigeons started the test in Context 1 (blue keylight) and half started in Context 2 (red keylight). After each two blocks of houselight-intensity test stimuli, the contexts were alternated.

\section{Results and Discussion}

On the last session of Phase-1 training, the subjects yielded a mean of $92.4 \%$ of total responses to $S+$ (range $85 \%-100 \%$ ). All subjects had to be reshaped to peck the key when the discrimination was reversed at the start of Phase 2. Nevertheless, by the sixth session of Phase-2 training, all subjects had mastered the discrimination, with a mean of $91.7 \%$ of total responses to $S+$ (range $87 \%-100 \%$ ).

Figure 3 presents the individual houselight-intensity generalization gradients obtained under each key-color context and the group mean gradients obtained under each context. There were no systematic differences between the test data of subjects that had started the test in Context 1 and those that had started it in Context 2. The gradients show strong evidence of conditional control by the key-color contexts, with both maximal and minimal responding at or near the $\mathrm{S}+$ and $\mathrm{S}-$ values in each context.

In the original study by Thomas et al. (1985) in which key color failed to gain conditional control over line-angle discriminations, four sessions of training on the original and on the reversal problems were administered. Because the discrimination between $\mathrm{HL}$ and $\overline{\mathrm{HL}}$ conditions is somewhat more difficult than that between blue and red key colors, six sessions of training were administered on each problem in Experiment 3. This difference in amount of training cannot account for the difference in results, however. Recall that Thomas et al. (1987) found that floor tilt and texture cues were ineffective as conditional cues in the single reversal paradigm despite 15 sessions of training on the original and on the reversal color discrimination problem. In pilot work in this laboratory with contextual cues that were ineffective (e.g., floor tilt and texture, auditory frequency, pure tone vs. white noise, etc.), no amount of single reversal training succeeded in producing conditional control by those cues. However, an alternative training procedure, such as the CSDR procedure used in the present Experiment 2, was generally successful.

The results of Experiment 3 indicate that in a combination of houselight and key-color cues, a conditional relationship is formed readily regardless of which cue serves a conditional role and which cue serves a discriminative role. It is possible, of course, that conditional relationships are formed most readily when one of the cues (either one) is global and the other is local. Thus, these results did not directly address the stimulus-compounding interpretation of the failure of key color to gain conditional control over a line-angle discrimination in the Thomas et al. (1985) experiment. For this purpose, another procedure was required, one that employed the same line-angle

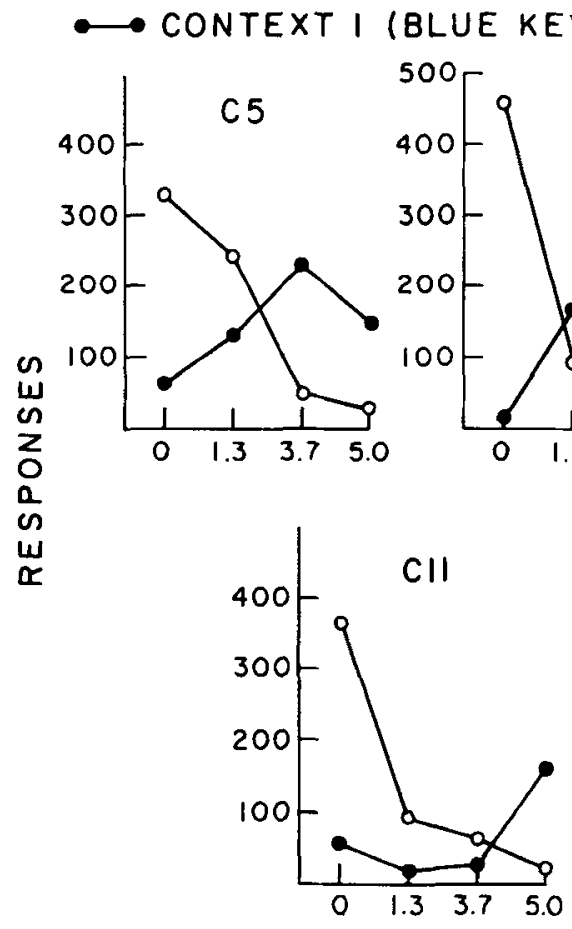

LIGHT)

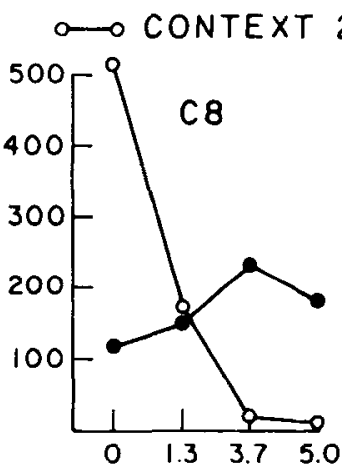

2 (RED KEYLIGHT)
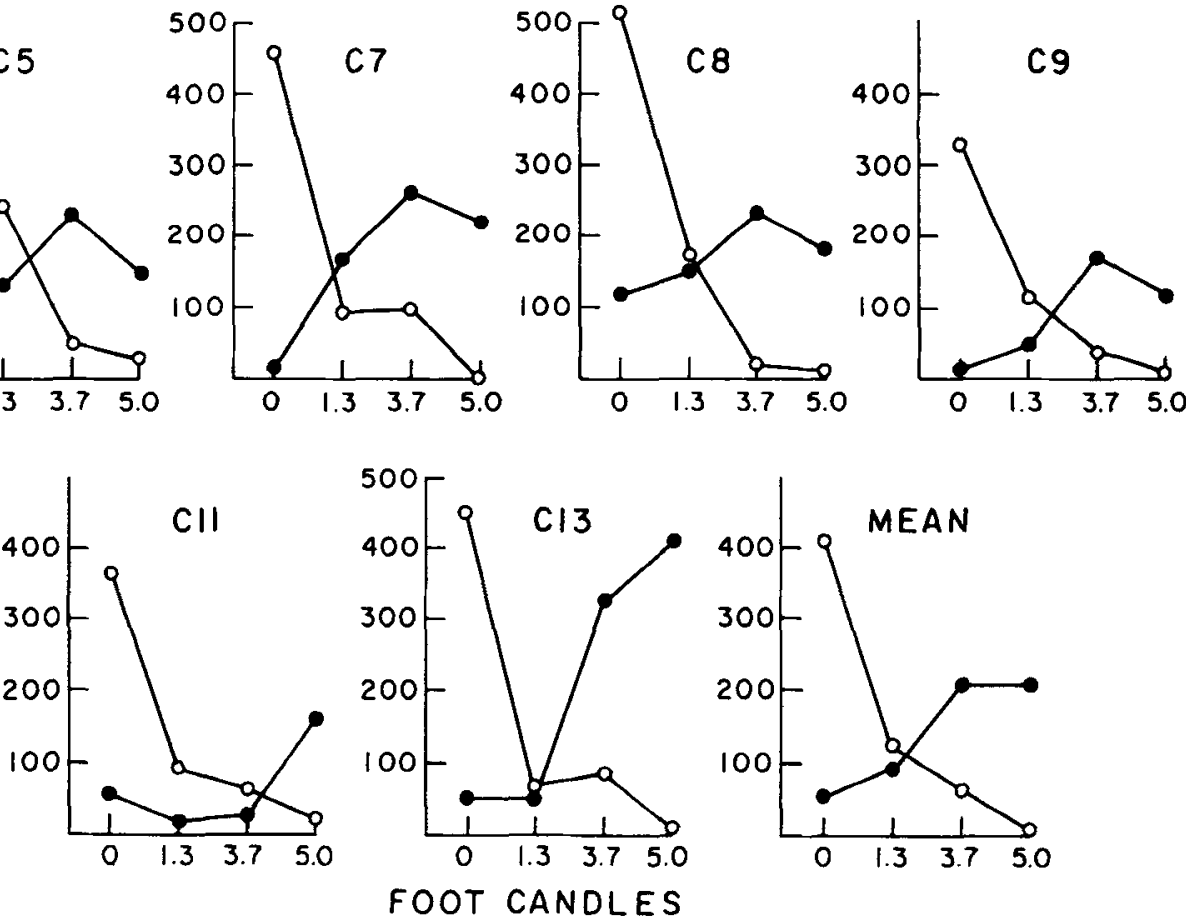

Figure 3. Individual and group mean houselight intensity generalization gradients in two different key-color contexts following single reversal training. 
and key-color cues used by Thomas et al. (1985) and that showed that a conditional relationship could be formed between these cues when they were presented in such a way as to preclude their being confounded. In the procedure that was adopted for Experiment 4, the key-color conditional cue preceded and then accompanied the presentation of the line-angle discriminative cues. The prior presentation of the key-color element was expected to prevent the formation of a compound of the line-oncolor stimulus, but the simultaneous presentation of the lines and color should have maximized the opportunities to leam the conditional relationship that existed between them.

\section{EXPERIMENT 4}

\section{Method}

Subjects. The subjects were 7 experimentally naive pigeons, maintained as in Experiment 1.

Apparatus. The apparatus was the same as that used in Experiment 1.

Procedure. All subjects were magazine-trained and then shaped by the method of successive approximations to peck the key that was illuminated by a $490-\mathrm{nm}$ (blue) light, with a white vertical $\left(90^{\circ}\right)$ line superimposed upon it. Over the next several days, they were exposed to a VI schedule with gradually increasing interreinforcement intervals until a VI 30-sec schedule was in effect. Phase 1 of discrimination training was begun on the next day. During discrimination training, responding was reinforced on a VI 30-sec schedule during $\mathbf{S}+$ periods and extinguished during $\mathbf{S}-$ periods. Each trial consisted of presenting the key color for a 20-sec period (during which reinforcement was unavailable) followed by either the $S+\left(90^{\circ}\right)$ or $S-\left(0^{\circ}\right)$, with the white line superimposed on the key color for the next $25 \mathrm{sec}$. Blackout periods of 5 -sec duration separated trials, and $\mathbf{S}+$ and $\mathbf{S}-$ trials were arranged in an unsystematic order. Six daily sessions of Phase-1 discrimination training were given. Phase- 2 reversal training was started on the next day. In Phase 2, the $0^{\circ}$ line was S + and the $90^{\circ}$ line was $S-$, and all trials started with the red $(606 \mathrm{~nm})$ keylight. All subjects began pecking the key within the first few minutes of the initial training session of Phase 2 . The subjects were trained for six daily sessions in Phase 2, with trials and blackouts of the same duration as in Phase 1.

On the day after the completion of Phase 2, the subjects were tested for line-angle generalization in extinction. Stimulus presentations were of 25 -sec duration, separated by 10 -sec blackouts. The seven test stimuli, $0^{\circ}, 15^{\circ}, 30^{\circ}, 45^{\circ}, 60^{\circ}, 75^{\circ}$, and $90^{\circ}$ were arranged into random blocks, and eight different randomized blocks were presented to each subject. Half the subjects started the test in Context 1 and half started in Context 2. The context was changed after every two blocks of line-angle test stimuli. As in training, the key-color context preceded the presentation of the line-angle stimuli by $20 \mathrm{sec}$ and remained on during the presentation of the lines.

\section{Results and Discussion}

Because responding to the color when presented alone during the first $20 \mathrm{sec}$ of each trial was never reinforced, it dropped out by the third or fourth training session. When the reversal problem of Phase 2 was first presented, the pigeons' performances were disrupted, but they started to respond again within a few minutes. After responding to the red keylight with the superimposed lines was established, responding generalized to the red keylight when presented alone. Such responding dropped out after several sessions of Phase-2 training.

All subjects mastered Phase 1 of discrimination training, and on the sixth training session they yielded a mean of $91.3 \%$ of total responses to $\mathrm{S}+$ (range $88 \%-94 \%$ ). On the last session of Phase-2 reversal training, they averaged $88.6 \%$ of total responses to $S+$ (range $81 \%-91 \%$ ).

For each subject, a generalization gradient was obtained on the basis of its responses in each (key color) context. The two individual gradients of each subject, along with the group mean gradients under each condition are presented in Figure 4. The group mean gradients under the two context conditions show strong evidence of conditional control, with maximal and minimal responding at (or near) the appropriate $S+$ and $S$ - in each context. Although there was considerable variability in the individual subjects' gradients, none of them showed recency, and most showed good evidence of conditional control.

The results of Experiment 4 (and those of Experiment 3 ) indicate that a localized stimulus toward which responding is directed can serve effectively as a conditional stimulus following training with the single reversal paradigm. In view of the failure of key color to gain conditional control over a line-angle discrimination when the stimuli were presented only simultaneously in the Thomas et al. (1985) experiment, it is clear that the sequential presentation of the colors and the lines was critical in the formation of the conditional relationship between them.

\section{GENERAL DISCUSSION}

Thomas et al. (1985) had suggested that perhaps the reason that the houselight condition was such an effective conditional cue was that it permitted the pigeons to identify the place where food had been earned and that pigeons may be biologically prepared to engage in such learning. They reported an experiment in which black and white stripes on the walls of the operant chamber were also effective, although not as effective as the houselight cues. Thomas et al. (1987) proposed that floor tilt and texture would also provide place information and might therefore serve as effective conditional cues in the single reversal paradigm, but their research indicated otherwise. Nevertheless, it could be argued that global visual cues are particularly relevant, especially when feeding behavior is involved. The results of our Experiment 1, however, make the place learning interpretation of houselight effects untenable. The results also indicate that the question that motivated much of our research (i.e., What are the characteristics of an effective conditional stimulus?) is ill-conceived. Because a conditional relationship involves both conditional and discriminative cues, the consideration of either one in isolation is doomed to failure. A more proper question would be, Which combinations of conditional and discriminative cues are effective in establishing a conditional relationship? 


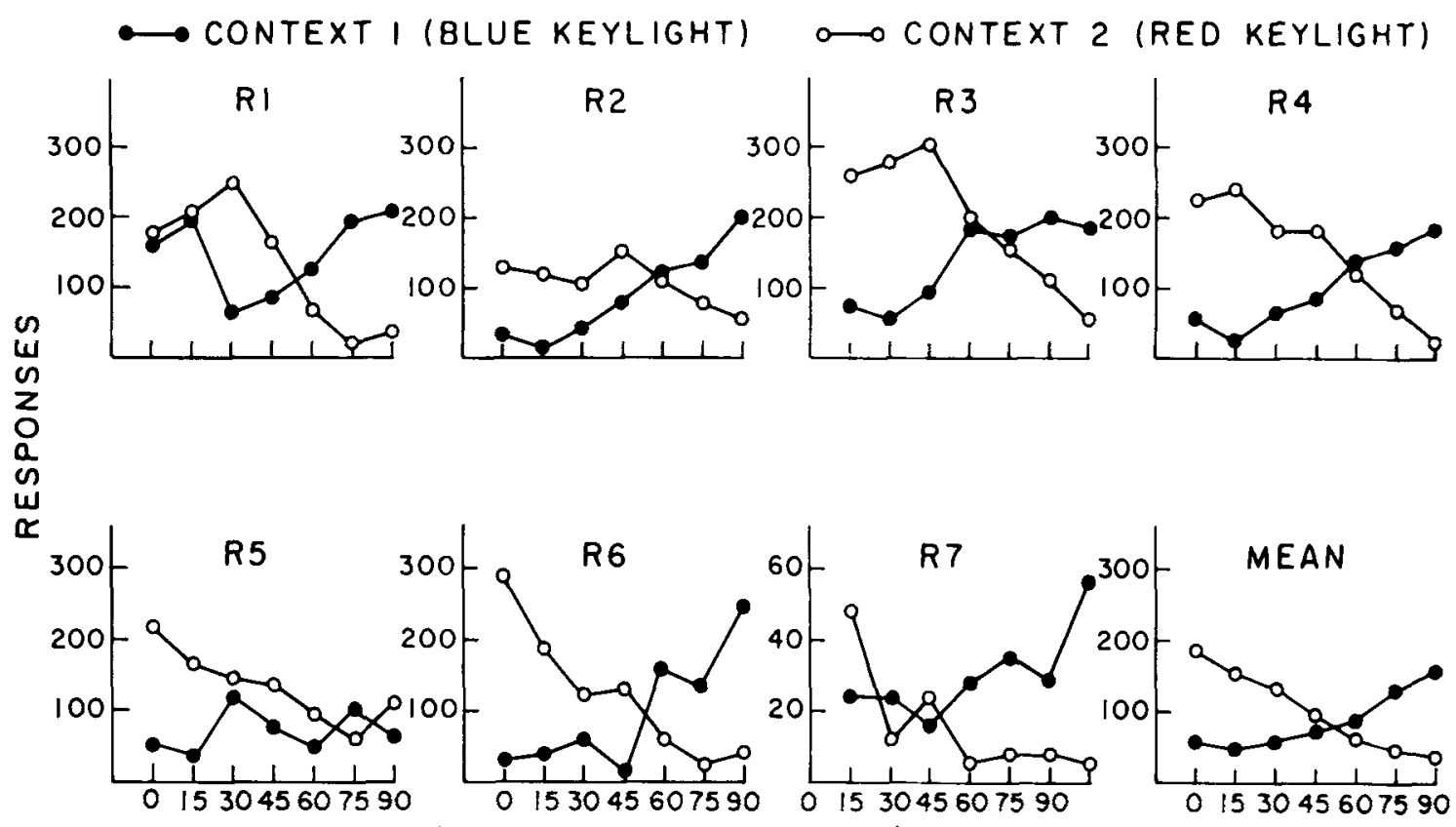

ANGULAR ORIENTATION (DEGREES)

Figure 4. Individual and group mean line-angle generalization gradients in two different key-color contexts following single reversal training in which the conditional and discriminative cues were temporally separated.

When a combination of cues (e.g., houselight and key color) is effective, is one of these cues, by virtue of its physical characteristics, more effective in one role (conditional or discriminative) than the other? A definitive answer to this question is not available. We cannot directly compare the slopes of the houselight intensity generalization gradients obtained in Experiment 3 with the wavelength gradients obtained in our other studies without psychophysical scaling of the stimuli along the two dimensions. It seems likely that the houselight intensity differences (between adjacent values) are less discriminable than are the wavelength differences, and this, alone, may account for obtained differences in gradient slopes. It is clear, however, that a localized stimulus (key color) can serve effectively in a conditional capacity. This finding is particularly interesting because conditional cues are traditionally background in a perceptual sense, as well as in a functional sense. Clearly, however, a foreground cue can serve in a background capacity, that is, as a conditional cue.

The difficulty with which conditional discriminations have been acquired in past studies with pigeons is commonly attributed to the cognitive demands inherent in the formation of a hierarchical relationship among the stimuli. A contributing factor, however, has probably been the use of conditional cues and discriminative cues in such a way that a psychological compound could be formed. Such compounding might be expected to hinder the perception of a hierarchical relationship between the constituent elements. In Experiment 4, the sequential presenta- tion of key-color and line-angle stimuli permitted the colors to acquire conditional control over the line-angle discriminations. In our work, when such global cues as those produced by houselight are combined with localized cues on the response key, conditional relationships are readily formed even with simultaneous presentation, quite possibly because the global and local cues are not compounded.

The finding that stimulus compounding or configuring hinders, rather than supports, conditional discrimination learning seems inconsistent with an interpretation of such learning called by Carter and Werner (1978) the configuration model. It is important to emphasize, therefore, that Carter and Werner do not refer to configuring in the perceptual or gestalt sense of a combination of cues forming a unitary new stimulus. All that they mean by configuring is that "all aspects of the stimulus situation or configuration, that can be detected by the subject come to exert some control over the discriminative response" (Carter \& Werner, 1978, pp. 566). For Carter and Werner, the configuration model would deny that the learning of hierarchical relations or rules (e.g., " if blue, then vertical') underlies conditional discrimination performance. Our results are silent on the issue of whether such rule learning takes place, but they indicate that configuring in the technical perceptual sense surely is not the basis for the mastery of the conditional discrimination task.

It would be of interest to determine whether a simultaneous presentation of key-color and line-angle cues would 
permit the development of a conditional relationship if the cues were separated spatially (e.g., on different keys), rather than temporally, as in Experiment 4. Either procedure might prevent a psychological compounding of the cues. We had selected a temporal, rather than a spatial, separation, in part, because Holland's (1983) work on occasion setting in Pavlovian conditioning in rats had suggested that sequential presentation facilitates the development of conditional relationships.

There is a striking procedural parallel between Rescorla's (1985) work on conditioned facilitation in pigeons and our work on conditional discrimination learning via the single reversal paradigm. As we did in our studies, Rescorla either used global conditional cues and localized and discrete CSs or he separated the cues temporally. The reason for his use of these procedures is different from ours, however. In Pavlovian occasion setting or facilitation, the conditional discrimination is of the feature positive sort (Jenkins \& Sainsbury, 1969), that is, AB+, A- . If responding occurs in the presence of $A B$, but not in the presence of $A$ when presented alone, it must be determined that such responding is based upon a conditional function of $B$ rather than on the simple acquisition of associative strength to $A$. This determination can be made if the response to $B$ is topographically dissimilar from the response to A (e.g., keypecking to a localized, but not to a global, visual stimulus) or if the responses occur at different points in time. In our conditional discrimination problems, the conditional cue accompanied both positive and negative discriminative stimuli; thus, the performance that resulted could not be attributed to any direct association between those cues and operant responding.

Indeed, the parallel between our procedures and those of Rescorla with Pavlovian preparations may be merely coincidental. The conceptual analog of a Pavlovian facilitator is not an operant conditional cue, but rather it is a discriminative cue. Discriminative cues signal a relationship between two other events-a response and a reinforcer. Thus, an operant conditional relationship involves a four-term contingency relating a conditional cue to a discriminative cue, to a response, to an outcome (see Sidman, 1986). Given the complexity of a four-term contingency, perhaps it should not be surprising that a satisfactory account of the factors that contribute to the formation of operant conditional relationships is not yet within our grasp.

\section{REFERENCES}

Boneau, C. A., HoniG, W. K. (1964). Opposed generalization gradients based upon conditional discrimination training. Journal of $E x$ perimental Psychology, 66, 89-93.

Carter, D. E., Werner, T. J. (1978). Complex learning and information processing by pigeons: A critical analysis. Journal of the Experimental Analysis of Behavior, 29, 565-601.

Holland, P. C. (1983). Occasion-setting in Pavlovian feature positive discriminations. In M. L. Commons, R. J. Herrnstein, \& A. R. Wagner (Eds.), Quantitative analyses of behavior: Discrimination processes (Vol. 4, pp. 183-206). New York: Ballinger.

HoNIG, W. K., URCUIOLI, P. J. (1981). The legacy of Guttman and Kalish (1956): 25 years of research on stimulus generalization. Journal of the Experimental Analysis of Behavior, 36, 405-445.

JENkINS, H. M., SAINSBURY, R. S. (1969). The development of stimulus control through differential reinforcement. In N. J. Mackintosh \& W. K. Honig (Eds.), Fundamental issues in associative learning (pp. 123-161). Halifax: Dalhousie University Press.

LASHLEY, K. (1938). Conditional reactions in the rat. The Journal of Psychology, 6, 311-324.

LoLoRDo, V. M. (1979). Selective associations. In A. Dickinson \& R. A. Boakes (Eds.), Mechanisms of learning and motivation: $A$ memorial to Jerzy Konorski (pp. 367-399). Hillsdale, NJ: Erlbaum.

Rescorla, R. A. (1985). Conditioned inhibition and facilitation. In R. R. Miller \& N. E. Spear (Eds.), Information processing in animals: Conditioned inhibition (pp. 299-326). Hillsdale, NJ: Erlbaum.

RICHARDS, R. W. (1979). Stimulus control following training on a conditional discrimination. Animal Learning \& Behavior, 7, 309-312.

Sidman, M. (1986). Functional analysis of emergent verbal classes. In T. Thompson \& M. D. Zeiler (Eds.), Analysis and integration of behavioral units (pp. 213-245). Hillsdale, NJ: Erlbaum.

Thomas, D. R., \& Curran, P. J. (1987). The role of response directedness in discriminative and conditional stimulus control. Bulletin of the Psychonomic Society, 26, 378-380.

Thomas, D. R., Goldberg, H. (1985). Conditional discrimination learning by pigeons: The role of training paradigms. Bulletin of the Psychonomic Society, 23, 256-258.

Thomas, D. R., McKelvie, A. R., MaH, W. L. (1985). Context as a conditional cue in operant discrimination reversal learning. Joumal of Experimental Psychology: Animal Behavior Processes, 11, 317-330.

Thomas, D. R., McKelvie, A. R., Ranney, M., \& Moye, T. B. (1981). Interference in pigeons' long-term memory viewed as a retrieval problem. Animal Learning \& Behavior, 9, 581-586.

Thomas, D. R., Stengel, T., Sherman, L., \& Woodford, M. (1987). Factors affecting conditional discrimination learning by pigeons. Journal of the Experimental Analysis of Behavior, 48, 277-287.

(Manuscript received December 3, 1987; revision accepted for publication May 10,1988 .) 